\title{
Enterprise Architectures in E-Governments Studies: Why, What and How?
}

\author{
Hong Guo ${ }^{1,2(\bowtie)}$ (D) and Shang $\mathrm{Gao}^{3}$ (D) \\ 1 Anhui University, No. 111 Jiulong Road, Hefei, People's Republic of China \\ homekuo@gmail.com \\ ${ }^{2}$ Norwegian University of Science and Technology, Sem Saelands vei 7-9, \\ Trondheim, Norway \\ 3 Örebro University, Fakultetsgatan 1, Örebro, Sweden \\ shang.gao@oru.se
}

\begin{abstract}
Enterprise Architecture (EA) is an important tool when developing e-governments and smart cities as it can help improve the alignment between business goals and Information and Communication Technologies (ICT) implementations. Although some studies have been performed to study the applications of EA in public sectors, governments, and cities, most of such studies are scattered and there is no strong research stream. As a result, it is difficult to effectively accumulate relevant knowledge and experiences. In this research, we attempt to explore research streams and trends by analyzing why existing studies were conducted, what outcomes were produced, and what methods were used in these studies. Starting from these three questions, a thematic framework was developed, and a literature synthesis was presented. The result shows the complexity of this area, the importance of balancing technical factors and non-technical factors, the challenges brought by nonfunctional requirements. Despite the importance of EA frameworks, few studies have been found in which government or city relevant requirements were addressed in a general way. Such findings are expected to provide useful insights for possible future research in this area.
\end{abstract}

Keywords: Enterprise architecture $\cdot$ E-government $\cdot$ Public sector $\cdot$ Smart cities

\section{Introduction}

More than half of the world's population lives in cities [1]. And it was predicted that by 2050, the world population will reach nearly 10 billion [2]. By leveraging the power of Information and Communication Technologies (ICT) in public sectors or governments and making a city "smart", e-governments and smart cities are emerging as a strategy to mitigate problems generated by the urban population growth and rapid urbanization, improve the efficiency of urban management and bring better life to residents. However, as a giant system which involves various kinds of stakeholders, new technologies and complicated ICT subsystems, challenges such as complexity, interoperability and alignment between business goals and ICT implementations have been met [3, 4]. 
Especially, with the ever-expanding scale of cities, the continuous updating of ICT, and the higher expectations of people for a better life, how to make the advantages of ICT more effective and efficient becomes a problem. Enterprise Architecture (EA) has been adopted as an important tool to tackle such challenges [5] as they can help integrate ICT to achieve urban management, business operations and personal life goals.

Although some earlier studies on applying EA in public sectors, e-governments and smart cities have been performed, existing studies in this area are scattered and no strong research stream has been formulated [6]. As a result, general knowledge regarding EA in e-governments is difficult to be accumulated and be reused elsewhere. And in return, practices cannot be improved efficiently accordingly. To address this problem, we propose to characterize existing studies in this field by answering three important questions: why one research on applying EA in e-government or smart cities was required (motivation), what kind of outcome was contributed (contribution), and how the research was performed (method). These three questions have been thought fundamental and used widely to get an overview of studies in specific fields [7-9]. Starting on this characterization theme, we developed a framework and performed initial explorations by analyzing and grouping a set of studies in this area based on the framework. The result was presented as a literature synthesis. Findings from this synthesis are expected to bring some insights for possible future research directions.

The rest of this article is organized as below. In Sect. 2, we introduce how we developed the thematic framework and selected scientific articles to perform the literature synthesis. In Sect. 3, we present the literature synthesis. We then discuss the synthesis result and present some findings accordingly in Sect. 4. Later, Sect. 5 introduces some related works. Lastly in Sect. 6, we talk about limitations of this study, point out some possible future research directions, and conclude this paper.

\section{Methods}

We aim to disclose fundamental knowledge about main research streams, critical issues, and possible future trends in the area of applying EA when developing ICT systems for public sectors, governments, and cities. To address this, widely used three questions, namely Why, What, and How were employed in this study. These three questions have been used in various domains such as $[8,10,11]$ to help organize and analyze existing studies. Starting from them, we extracted four or five answers to each question through a simplified research synthesis [12] based on a sample of ten highly relevant studies. Because we have read these papers previously, we are familiar with the depth and breadth of the evidences in these studies. Further, with the three questions as the structure, we then identify specific segments of text for each question, label, reduce overlap, and translate them into enumerated answers. The three questions together with the enumerated answers constitute a framework for further literature synthesis.

Later, we applied this framework to a larger set of studies and performed grouping and analysis. We searched keywords in titles of scientific articles to find relevant studies in Google Scholar. The keywords include combination of "Enterprise Architecture" and "cities", "government", or "public sector". Although our original interest 
domain is smart city, papers regarding applying EA in smart cities are rare. We expand the domains to e-government and public sectors as they are highly relevant, and the concepts started to be used interchangeably during recent years [13]. Due to time and resources constraints, we put our focus on more recently published and highly qualified papers by restricting publication years and checking the relevance with this study. We searched papers that have been published between 2009 to 2019. After excluding duplicated papers and papers that were not written in English or full texts are not available, we collected 35 scientific papers. The overview of the synthesis framework is presented in Table 1. And the detailed meaning for each category (answer) in the framework will be introduced together with the literature synthesis in Sect. 3.

Table 1. A framework for a literature synthesis

\begin{tabular}{l|l|l}
\hline Why (Motivation) & What (Contribution) & How (How) \\
\hline - Gaining general knowledge & $\bullet$ Perspectives & $\bullet$ Literature analysis \\
- Technical motivation & $\bullet$ Review & $\bullet$ Case studies \\
- Non-technical motivation & $\bullet$ Design artifacts & $\bullet$ Survey \& interview \\
- Improving performance & $\bullet$ Frameworks & $\bullet$ Others \\
- Studies analysis & & \\
\hline
\end{tabular}

\section{Literature Synthesis}

The studies on the application of EA in public sectors, e-governments, and smart cities were examined based the following themes: RQ1: Why a study was performed (motivation); RQ2: What was produced from the study (contribution); and RQ3: How the study was conducted (methods) (see Table 1). The following subsections provide an overview of each theme.

\subsection{Why (Motivations)}

Research motivation describes why a study has been initiated. In addition, it provides information regarding which problems were expected to be solved by conducting the research. Five types of motivations were identified as summarized in Table 2.

- Gaining general knowledge: This is to gain some general knowledge (definition, scope, challenges, and etc.) in the area;

- Technical motivation: This is to solve some technical problems;

- Non-technical motivation: The research was performed to solve some non-technical (managerial, social, or economic, and etc.) problems;

- Improving performance: The motivation was to improve some aspects (e.g., interoperability) of the performance;

- Gaining insights to studies: This is to analyze studies in the area (e.g., by performing a literature review). 


\section{Gaining General Knowledge}

Some studies were performed to obtain general knowledge of applying EA in governments. Such knowledge includes what has driven the adoption and use of EA in the Danish government [14], how EA was understood by public sector organizations in Finland [15], prominent reasons for investment failure in Nigerian government [16], challenges faced by the Malaysian public sector agencies [17], root causes of challenges faced by the organizations and important requirements for smart cities $[18,19]$, and if EA was useful as a reference for smart city development [20].

Table 2. Motivation of the researches

\begin{tabular}{|c|c|c|c|c|c|}
\hline & $\begin{array}{l}\text { General } \\
\text { knowledge }\end{array}$ & Technical & $\begin{array}{l}\text { Non- } \\
\text { technical }\end{array}$ & $\begin{array}{l}\text { Improving } \\
\text { performance }\end{array}$ & $\begin{array}{l}\text { Gaining } \\
\text { insights to } \\
\text { studies }\end{array}$ \\
\hline Literature & $\begin{array}{l}{[14,15,16,} \\
19,17,18, \\
20]\end{array}$ & $\begin{array}{l}{[21,22,} \\
23,24, \\
25,26]\end{array}$ & $\begin{array}{l}{[27,28,} \\
29,30, \\
31,32]\end{array}$ & $\begin{array}{l}{[33,34,35,36,37,} \\
38,39,40,41,42, \\
43]\end{array}$ & $\begin{array}{l}{[44,45,46,} \\
47,6]\end{array}$ \\
\hline
\end{tabular}

\section{Technical Motivation}

Some studies have been motivated to satisfy technical requirements. Such efforts are like an agile EA framework proposed to support government transformation with cloud technology enabled [21], an EA based approach to manage state-level data in real time in the Indian public sector of healthcare [22], a method to find patterns for enterprise information architecture in governments [23], a proposal for a framework for ICT governance [25], and a government EA framework to support big and open linked data and cloud computing [24, 26].

\section{Non-technical Motivation}

On the other side, some studies emphasized the importance of non-technical aspects when applying EA in governments. It was underscored that simply taking an IT perspective is a serious mistake [27], EAs were primarily product oriented while sociopolitical aspects were often neglected [29]. Non-technical factors were ignored or considered less significant than technical ones [30]. To address such non-technical issues, institutional aspects of applying EA in governments were investigated [28, 31, 32]. EA did not create administrative or political transformation by itself. Instead, fundamental transformation can only be achieved when the institutional force at the micro and macro level promotes transformation [28]. How institutional change helped practitioners legitimize EA practices [32] and how EA programs have been institutionalized in Vietnam [31] were investigated. Inductive communication and the deployment of experts to local contexts could be introduced to overcome struggles when applying EA to US governments.

\section{Improving Performance}

More studies looked at both technical aspects and non-technical aspects and focused on how to improve the overall performance. Ways of improving e-government performance in developing countries [39], lessons learned from the case of Finnish and Colombia government EA [37, 38] were investigated. Further, key factors for raising 
the maturity of government EA practices, such as management commitment and participation of business units, which were influenced by the perceived usefulness of the government EA efforts [35] were explored.

In particular, some studies focused on improving the interoperability. This could be achieved by means of a procedure to provide guidance on how to rationally specify scope dimensions for a complex enterprise such as a government [42] and a metamodel approach to design government EA database and communication with agencies [36]. EA was also introduced as an information systems architecture approach to solve interoperability challenges at different levels of government [33].

In addition to interoperability, architectural design principles to better support the decentralization/centralization relationships among central and local governments in the Netherlands (1980s-2004) [34], nation-wide strategy and holistic guiding plans to better support broad government integration and alignment between business processes and IT implementations [43], an EA framework to better align IT needs and organization business [40] and to enhance the support of transparency of processes, information and applications in public organizations were investigated [41].

\section{Gaining Insights to Studies}

Several articles were motivated to gain insights of existing studies themselves. Thus efforts have been done to review government EA papers published in China [44] and 71 articles about applying EA in public sectors published during the past 15 years [6]. More specifically, smart city frameworks were reviewed [46, 47] from an EA perspective or based on EA requirements, several EA frameworks were compared and mapped to provide guidance on how to choose EA frameworks [45].

\subsection{What (Contributions)}

In the information system field, there are primarily two main research genres, namely behavior science and design science [48]. For behavior science, people are trying to better understand the world and usually contribute with some perspectives. For design science, people usually construct complicated artifacts such as a model, a method or an application to extend the ability to manage the world. Specifically, the literature review can be thought as one specific way to understand the world. And EA frameworks can be thought as specific artifacts. More information is presented in Table 3.

- Perspectives: The research was performed by providing some perspectives to understand the world;

- Review: Some literature analyses was provided;

- Design artifacts: Artifacts were proposed to extend the ability to manage the world;

- Frameworks: Some EA frameworks used in governments were proposed.

Table 3. Contribution of the studies

\begin{tabular}{l|l|l|l|l}
\hline & Perspectives & Review & Artifacts & EA frameworks \\
\hline \multirow{2}{*}{ Literature } & {$[33,27,28,14,29,35$,} & {$[45,44$,} & {$[34,36,39$,} & {$[38,37,21,22,41$,} \\
& $15,16,19,30,17,18,32]$ & 46,6, & $23,31,43$, & $40,24,25,20,26]$ \\
& & $47]$ & $42]$ & \\
\hline
\end{tabular}




\section{Perspectives}

Some studies contributed by presenting understandings on the problem of interests, such as the role of EA in aligning business and IT in Nigerian government [16] or the statement that EA in government was to a large extend driven by fashion while compliance and imitation primarily drove the EA adoption [14, 28]. Therefore, fundamental transformation to organizational tasks can only be achieved when transformation is promoted by institutional forces. Similarly, it was reported that current EAs were primarily product oriented, with their sociopolitical aspects neglected often [29], and simply taking an IT perspective on EA as a prerequisite to e-government implementation was a serious mistake [27]. Both technical and nontechnical factors should be considered [30], and two key institutionalization techniques, inductive communication and deployment of experts to local contexts, might help overcome the struggles of translating new practices [32].

More concrete contributions were produced in some studies such as how EA was understood by public sector authorities [15], twenty challenges faced by the public sector agencies [17], sixteen problems and eight root causes in the context of public sectors [18] when developing and implementing EA. Such contributions also include important quality and functional requirements and a conceptual architecture framework to address requirements [19], key factors for raising the maturity of the government EA practice [35] and a conceptual framework addressing different interoperability types in institutional level, sector level, and national level [33].

\section{Review}

Some studies review scientific articles on the area of applying EA in governments or public sectors [6, 44], published in China in particular [44]. Some studies classified or compared artifacts such as four EA frameworks [45] and smart city frameworks [46, 47].

\section{Design Artifacts}

For design science studies, principles, guidelines, models or methods have usually been produced as the contributions. For instance, architectural design principles were identified [34], meta-models to design government EA database were presented [36]. Further, an EA development life cycle [43], a procedure to specify critical aspects in scoping government EA efforts [42], and a method to find enterprise information architecture patterns [23] were introduced. More such artifacts include a benefit model to measure government performance [39] and how rules, norms, and values influenced EA programs in different phases institutionally [31].

\section{EA Frameworks}

In several papers, government EA frameworks have been presented as the main contribution of the studies. For instance, government EA frameworks that have been used in Colombia [38], Finland [37], Indonesia [20], Brazil [41] were presented. More specifically, the EA framework including the architecture and methodology to support using big data and cloud computing was described [24, 26]. Similarly, the use of an agile EA framework to develop and implement the cloud-enabled government was proposed [21]. An government EA framework developed based on TOGAF and SONA that have been used in Indonesia was presented [40]. The modified EA of the health management information system at India was studied [22]. What is more, an ICT 
governance framework [25] and a theoretical framework to manage information systems at different levels in government were introduced.

\subsection{How (Methods)}

Methods to perform a research or evaluate contributions were identified in Table 4.

- Literature analysis: The research was performed by comparatively in-depth literature analysis (classification, comparison etc.) and usually resulted in a table for better visualization;

- Case study: Case studies were performed, or examples were provided, usually in labs, and in a qualitative way;

- Survey and interview: Surveys, questionnaires, interviews, focus group, and etc. were utilized, usually outside labs, and in a quantitative way;

- Others: Research methods other than above were used.

Table 4. Methods of the studies

\begin{tabular}{l|l|l|l|l}
\hline & $\begin{array}{l}\text { Literature } \\
\text { analysis }\end{array}$ & Case study & Survey \& Interview & Others \\
\hline Literature & {$[44,45$,} & {$[15,16,36,21,38,37$,} & {$[34,28,14,35,29,19$,} & {$[27$,} \\
& $46,6,47]$ & $\begin{array}{l}30,41,23,40,24,20,43, \\
26]\end{array}$ & $\begin{array}{l}22,39,18,31,17,32,25, \\
42]\end{array}$ & $33]$ \\
& & $26]$ & \\
\hline
\end{tabular}

\section{Literature Analysis}

In addition to typical literature review studies [6, 44], some other studies performed comparatively in-depth literature analysis for smart cities frameworks [46, 47] and EA frameworks [45]. For some studies such as [32], although literature analysis was also performed, we do not include it in this group as its primary method was interview.

\section{Case Studies}

Performing case studies is a frequently used method in this area. Examples, demos or case have been presented regarding the practices of applying EA in governments of different countries such as Indonesia [20, 43], Korea [36], Australia [21], Colombia [38], Finland [37], Brazil [41], and Portugal [23].

Some studies employed theories to improve the rigorous of research methods. For instance, activity theory was used to help revealing the importance of non-technical factors in the deployment of EA [30]. Action design was used when performing the longitudinal case study of government EA adoption in Finnish public sector [24]. TOGAF and SONA were used to develop EAs in the case of the volcanoes monitoring system [40] and EA score card was used for validation and assessment. In some studies, Design Science Research (DSR) approach was adopted as the overall method while validation and verification of the proposed framework was performed with more specific methods [26]. 
Most studies in this group have been performed in a qualitative way except for [16] and [15]. In [16], IT investments by Nigerian government was studied and according to the quantitative result, the reasons of investment failure were identified. While in [15], a content analysis was conducted (both qualitatively and quantitatively) on the statements of public sector organizations about the proposed EA in Finland.

\section{Survey \& Interview}

A survey or a questionnaire is widely used to quickly and efficiently gather as well as analyze data from a population. More quantitative studies were performed in this group than in the Case Studies group. In these studies, a survey to identify smart city important requirements [19], a questionnaire to identify the maturity level in city councils for visualizing the governance maturity model [25], a survey to disclose the fact that current EAs were primarily product oriented [29] and a survey involving 33 agencies to figure out maturity factors of the government EA practice were conducted.

Interviews were also employed to obtain open and unstructured opinions from a population [18, 22, 28, 31, 32]. In some studies, interviews were utilized in addition to case studies. In [17], a multiple case study was utilized in addition to data collected through interviews. One instance is the comparative case studies together with semistructured interviews used to gather data [34]. In addition, interviews have been used together with other methods such as surveys [39] and focus groups [14]. A field demo was another way to help gather on-spot data [42].

\section{Others}

In some studies, no specific research method has been explicitly specified such as [27, 33]. In the studies, some discussion and arguments were presented.

\section{Discussion}

By identifying and grouping motivations, contributions, and methods of existing studies, some research streams and trends can be found below.

Basing on the synthesis of motivations of existing studies, we found that, despite of the fact that applying EA in e-governments is not a new tradition, there have been continuously studies aiming to achieve understandings about some general knowledge, such as challenges, problems, and root causes. This might indicate the potential complexity of EA and EA application. As a result, more studies have been done in a quantitative way in order to gain more objective, generic, and precise insights. In addition to technical factors, non-technical factors also play important roles when applying EA in e-government development. However, along with the development of new technologies such as big data and cloud computing during recent years, how to apply them in this area has also become a rising hot spot. Another stream of research is about achieving non-functional requirements. Around one third of selected studies have described their efforts to improve specific aspect of the overall performance of egovernments, which involves both technical factors and/ or non-technical factors generally.

Concerning research contributions, we found many studies were performed and some perspectives were produced as the results. This was partly caused by the 
motivation of gaining general knowledge of such studies. On the other hand, compared to proposing general design artifacts, proposing EA Frameworks has been a continuous research stream for the past five years. For this part, most studies focused on how to improve the practice of using EA, while few studies addressed how to improve EA according to the practices.

Further, the synthesis on research methods disclosed that, case studies, surveys \& interviews have been the dominant methods that have been adopted. This might be due to the fact that non-functional factors, including human factors, play important roles in this area. Due to limited and unmatured benchmark and evaluation methods that are available, achieving satisfaction of stakeholders are important. Particularly, we found that in many studies, EA frameworks were proposed in local contexts. However, it was not intensively clarified that what unique characteristics such a framework had compared with other widely used ones, and what was the use of such a framework in a general scenario. Despite that new requirements of e-government development have arises when cities are expected to be smarter and more sustainable, few studies were found which addressed such government or city specific requirements.

\section{Related Work}

There are some related works. For example, [44] reviewed literature that have been published in Chinese journals about EA in government departments during past six years until 2013. In [16], the authors focused on investments of information technologies. And in [6], the authors collected and analyzed articles regarding applying EA in public sectors that have been published until 2017. Compared with them, present research collected more recently published articles. In [6], it was mentioned that studies in the area of interests have been quite scattered and there was no main stream of research. As a result, knowledge and experiences cannot be accumulated in an efficient way. In present research, we selected articles and analyzed motivations, contributions and methods, and provided insights on the streams and trends based on the review results.

\section{Conclusions}

In this article, we propose to answer three fundamental questions (why, what, and how) on studies regarding applying EA in public sectors, e-governments and smart cities to gain fundamental knowledge for future research. By analyzing and grouping motivations, contributions, and methods of researches presented in 35 selected articles, some findings are disclosed based on a literature synthesis. The result shows the complexity of this area, the importance of balancing technical \& non-technical factors, the importance and challenges brought by non-functional requirements. Despite the importance of EA framework, few studies have been found in which government or city specific requirements have be addressed in a general way. Such findings are expected to provide useful insights for future possible research in this area. 
There are limitations for present research. We provided a literature analysis and synthesis on 35 articles that were selected from a literature search. It is possible that some research streams and trends could not be disclosed due to the restricted scope. Therefore, we plan to expand the scope and validate our results by performing a systematic review. In addition, based on the results of this article, we have scoped and defined several more specific and concrete research projects in this area.

Acknowledgement. This research is financially supported by The European Research Consortium for Informatics and Mathematics (ERCIM).

\section{References}

1. UN: World Urbanization Prospects 2018 (2018)

2. UN: World population projected to reach 9.8 billion in 2050 , and 11.2 billion in 2100 - says UN (2019)

3. Höjer, M., Wangel, J.: Smart sustainable cities: definition and challenges. In: Hilty, L.M., Aebischer, B. (eds.) ICT Innovations for Sustainability. AISC, vol. 310, pp. 333-349. Springer, Cham (2015). https://doi.org/10.1007/978-3-319-09228-7_20

4. Santana, E.F.Z., Chaves, A.P., Gerosa, M.A., et al.: Software platforms for smart cities: concepts, requirements, challenges, and a unified reference architecture. ACM Comput. Surv. (CSUR) 50(6), 78 (2018)

5. Saha, P.: Advances in Government Enterprise Architecture. IGI Global, Pennsylvania (2008)

6. Dang, D.D., Pekkola, S.: Systematic literature review on enterprise architecture in the public sector. Electron. J. E-Govern. 15(2), 57-154 (2017)

7. Kellner, M.I., Madachy, R.J., Raffo, D.M.: Software process simulation modeling: why? what? how? J. Syst. Softw. 46(2-3), 91-105 (1999)

8. Pauwels, K., Ambler, T., Clark, B.H., et al.: Dashboards as a service: why, what, how, and what research is needed? J. Serv. Res. 12(2), 175-189 (2009)

9. Van't Wout, J., Waage, M., Hartman, H., et al.: The Integrated Architecture Framework Explained: Why What How. Springer, Heidelberg (2010). https://doi.org/10.1007/978-3642-11518-9

10. Hamel, G.: The why, what, and how of management innovation. Harvard Bus. Rev. 84(2), $72(2006)$

11. Kiesler, S., Kraut, R.E., Koedinger, K.R., et al.: Gamification in education: what, how, why bother? Acad. Exch. Q. 15(2), 1-5 (2011)

12. Cruzes, D.S., Dyba, T.: Recommended steps for thematic synthesis in software engineering. In: 2011 International Symposium on Empirical Software Engineering and Measurement, pp. 275-284. IEEE (2011)

13. Mechant, P., Walravens, N.: E-government and smart cities: theoretical reflections and case studies. Media Commun. 6(4), 119-122 (2018)

14. Hjort-Madsen, K., Pries-Heje, J.: Enterprise architecture in government: fad or future? In: 2009 42nd Hawaii International Conference on System Sciences, pp. 1-10. IEEE (2009)

15. Lemmetti, J., Pekkola, S.: Understanding enterprise architecture: perceptions by the finnish public sector. In: Scholl, H.J., Janssen, M., Wimmer, M.A., Moe, C.E., Flak, L.S. (eds.) EGOV 2012. LNCS, vol. 7443, pp. 162-173. Springer, Heidelberg (2012). https://doi.org/ 10.1007/978-3-642-33489-4_14 
16. Enagi, M.A., Ochoche, A.: The role of enterprise architecture in aligning business and information technology in organisations: Nigerian government investment on information technology. Int. J. Eng. Technol. 3(1), 59-65 (2013)

17. Bakar, N.A.A., Kama, N., Harihodin, S.: Enterprise architecture development and implementation in public sector: the Malaysian perspective. J. Theor. Appl. Inf. Technol. 88(1), 176-188 (2016)

18. Dang, D.D., Pekkola, S.: Root causes of enterprise architecture problems in the public sector. In: PACIS, p. 287 (2016)

19. Kakarontzas, G., Anthopoulos, L., Chatzakou, D., et al.: A conceptual enterprise architecture framework for smart cities: a survey based approach. In: 201411 th International Conference on e-Business (ICE-B), pp. 47-54. IEEE (2014)

20. Saluky, S.: Development of enterprise architecture model for smart city. ITEJ (Inf. Technol. Eng. J.), 2(2) (2018)

21. Gill, A.Q., Smith, S., Beydoun, G., et al.: Agile enterprise architecture: a case of a cloud technology-enabled government enterprise transformation (2014)

22. Kaushik, A., Raman, A.: The new data-driven enterprise architecture for e-healthcare: lessons from the Indian public sector. Govern. Inf. Q. 32(1), 63-74 (2015)

23. Lemos, R.S.C.: Enterprise Information Architecture Patterns for Government (2016)

24. Valtonen, M.K.: Management structure based government enterprise architecture framework adaption in Situ. In: Poels, G., Gailly, F., Serral Asensio, E., Snoeck, M. (eds.) PoEM 2017. LNBIP, vol. 305, pp. 267-282. Springer, Cham (2017). https://doi.org/10.1007/978-3-31970241-4_18

25. Tanaka, S.A., de Barros, R.M., de Souza Mendes, L.: A proposal to a framework for governance of ICT aiming at smart cities with a focus on enterprise architecture. In: Proceedings of the XIV Brazilian Symposium on Information Systems, p. 52. ACM (2018)

26. Lnenicka, M., Komarkova, J.: Developing a government enterprise architecture framework to support the requirements of big and open linked data with the use of cloud computing. Int. J. Inf. Manage. 46, 124-141 (2019)

27. Bellman, B., Rausch, F.: Enterprise architecture for e-Government. In: Traunmüller, R. (ed.) EGOV 2004. LNCS, vol. 3183, pp. 48-56. Springer, Heidelberg (2004). https://doi.org/10. 1007/978-3-540-30078-6_9

28. Hjort-Madsen, K.: Institutional patterns of enterprise architecture adoption in government. Transform. Govern. People Process Policy 1(4), 333-349 (2007)

29. Janssen, M.: Sociopolitical aspects of interoperability and enterprise architecture in egovernment. Soc. Sci. Comput. Rev. 30(1), 24-36 (2012)

30. Shaanika, I., Iyamu, T.: Deployment of enterprise architecture in the Namibian government: the use of activity theory to examine the influencing factors. Electron. J. Inf. Syst. Dev. Countries 71(1), 1-21 (2015)

31. Dang, D.D., Pekkola, S.: Institutionalising enterprise architecture in the public sector in Vietnam. In: ECIS, p. 139 (2016)

32. Bui, Q., Levy, M.: Institutionalization of Contested Practices: A Case of Enterprise Architecture Implementation in a US State Government (2017)

33. Hjort-Madsen, K., Gøtze, J.: Enterprise architecture in government-Towards a multi-level framework for managing IT in government. In: 4th European Conference on e-Government, Dublin Castle, Ireland, pp. 365-374. Citeseer (2004)

34. Janssen, M., Kuk, G.: A complex adaptive system perspective of enterprise architecture in electronic government. In: Proceedings of the 39th Annual Hawaii International Conference on System Sciences (HICSS 2006), p. 71b. IEEE (2006) 
35. Ojo, A., Janowski, T., Estevez, E.: Improving government enterprise architecture practicematurity factor analysis. In: 2012 45th Hawaii International Conference on System Sciences, pp. 4260-4269. IEEE (2012)

36. Lee, Y.-J., Kwon, Y.-I., Shin, S., et al.: Advancing government-wide Enterprise Architecture-A meta-model approach. In: 2013 15th International Conference on Advanced Communications Technology (ICACT), pp. 886-892. IEEE (2013)

37. Lahtela, A., Kortelainen, P.: Government enterprise architecture in practice. In: Proceedings of the 14th European Conference on e-Government: ECEG, pp. 414-423 (2014)

38. Moreno, L.M.M., Páez, J.O.T., Parra, A., et al.: The Colombian government enterprise architecture framework. In: Proceedings of the 2014 Conference on Electronic Governance and Open Society: Challenges in Eurasia, pp. 38-41. ACM (2014)

39. Hanafiah, M.A.: Improving E-Government Performance Through Enterprise Architecture In Developing Countries: The Case Of The Indonesian Treasury. Flinders University of South Australia (2015)

40. Firmansyah, C.M., Bandung, Y.: Designing an enterprise architecture government organization based on TOGAF ADM and SONA. In: 2016 International Conference on Information Technology Systems and Innovation (ICITSI), pp. 1-6. IEEE (2016)

41. Nunes, V., Cappelli, C., Costa, M.: Promoting transparency in government through FACIN: the Brazilian government enterprise architecture framework. In: Workshop de Transparência em Sistemas, Rio de Janeiro (2016)

42. Nakakawa, A., Namagembe, F., Proper, E.H.A.: Dimensions for scoping e-government enterprise architecture development efforts. In: Panetto, H., Debruyne, C., Proper, H.A., Ardagna, C.A., Roman, D., Meersman, R. (eds.) OTM 2018. LNCS, vol. 11229, pp. 661679. Springer, Cham (2018). https://doi.org/10.1007/978-3-030-02610-3_37

43. Saiya, A.A., Arman, A.A.: Indonesian enterprise architecture framework: a platform for integrated and connected government. In: 2018 International Conference on ICT for Smart Society (ICISS), pp. 1-6. IEEE (2018)

44. Zheng, T., Zheng, L.: Examining e-government enterprise architecture research in China: a systematic approach and research agenda. Govern. Inf. Q. 30, S59-S67 (2013)

45. Al-Nasrawi, S., Ibrahim, M.: An enterprise architecture mapping approach for realizing egovernment. In: 2013 Third International Conference on Communications and Information Technology (ICCIT), pp. 17-21. IEEE (2013)

46. Mamkaitis, A., Bezbradica, M., Helfert, M.: Urban enterprise: a review of Smart City frameworks from an Enterprise Architecture perspective. In: 2016 IEEE International Smart Cities Conference (ISC2), pp. 1-5. IEEE (2016)

47. Bastidas, V., Bezbradica, M., Helfert, M.: Cities as enterprises: a comparison of smart city frameworks based on enterprise architecture requirements. In: Alba, E., Chicano, F., Luque, G. (eds.) International Conference on Smart Cities, pp. 20-28. Springer, Cham (2017). https://doi.org/10.1007/978-3-319-59513-9_3

48. Hevner, A.R., March, S.T., Park, J., et al.: Design science in information systems research. MIS Q. 28, 75-105 (2004) 